Estudios Románicos, Volumen 30, 2021, pp. 181-197

ISSN: 0210-4911

eISSN: $1989-614 \mathrm{X}$

DOI: https://doi.org/10.6018/ER.461171

\title{
DA ETIMOLOGIA À HARMONIZAÇÃO NEO-LATINA: MOTIVAÇÕES GRÁFICAS NA ESCRITURA DE A MAIS ENCANTADORA MULHER (1903) DO ROMANCISTA BRASILEIRO GONZAGA FILHO
}

(From etymology to neo-latin harmonization: graphic motivations in the writing of A mais encantadora mulher (1903), by the brazilian novelistt Gonzaga Filho)

\author{
Maria Hozanete Alves de Lima* \\ Universidade Federal do Rio Grande do Norte (UFRN)
}

\begin{abstract}
In this work, we reflect on the nature of the motivations defended by the Brazilian novelist Gonzaga Filho in his work A Mais Encantadora Mulher, published in 1903. In addition to the etymological, phonetic and prosodic propositions, the author makes use of a very particular proposition, which he names neo-latin harmonization. For the author, there was not, until the date of publication of his novel, in the Portuguese-speaking world, no single lexicon that would impose itself as an authority to be followed. Through the work of Gonzaga Filho, we observe the behavior of the metaorthographic movement that was unveiled, at the beginning of the 20th century, for the orthographic constitution of the Portuguese language in past synchronisms and its importance in the standardization process of spelling.
\end{abstract}

Keywords: History of Portuguese orthography; Past synchronisms; Graphic trends; Metaorthographic gestures; Gonzaga Filho; A Mais Encantadora Mulher.

Resumo: Neste trabalho, refletimos sobre a natureza das motivações defendidas pelo romancista brasileiro Gonzaga Filho em sua obra A Mais Encantadora Mulher, publicada em 1903. Além das proposições etimológicas, fonéticas e prosódicas, o autor

* Dirección para correspondência: Maria Hozanete Alves de Lima. Departamento de Letras. Centro de Ciências Humanas, Letras e Artes, Universidade Federal do Rio Grande do Norte (UFRN). Av. Senador Salgado Filho, S/n - Lagoa Nova, Natal - RN, 59078-970. (hozanetelima@gmail.com). 
faz uso de uma proposição muito particular, que ele nomeia de harmonia neo-latina. Para o autor, não havia, até a data de publicação de seu romance, no mundo lusófono, nenhum léxico que se impusesse como autoridade a ser seguida. Através da obra de Gonzaga Filho, observamos o comportamento do movimento metaortográfico que se desvelou, no início do século XX, para a constituição ortográfica da língua portuguesa em sincronias passadas e sua importância no processo de estandardização da grafia.

Palavras-chave: História da ortografia do português; Sincronias passadas; Tendências gráficas; Gestos metaortográficos; Gonzaga Filho; A Mais Encantadora Mulher.

\section{Introdução}

José Basileu Neves Gonzaga Filho (2/12/1849 - 9/09/1931), doutor em medicina e bacharel em Letras, é irmão da conhecida pianista e compositora brasileira Chiquinha Gonzaga (1847-1935). Não tão conhecido quanto à pianista, na modernidade, pouco se tem ouvido falar sobre seu extenso romance "A Mais encantadora Mulher - um romance para senhoras"1. Também, para quem se interessa por questões relacionadas à história da língua portuguesa, não há conhecimento de um único trabalho sobre a navegação do escritor sobre temas de ordem linguística, para a qual demonstrou profundo interesse. Um registro significativo de sua atuação nesse campo encontra-se no jornal brasileiro $O$ Globo: $\operatorname{Orgão}$ da Agencia Americana Telegraphica dedicado aos interesses do Commercio, Lavoura e Industria $(R J)$, no qual escreveu, nos meses inicias dos anos de 1882, uma seção intitulada Questões de linguística. A morfologia, a sintaxe, a semântica e, especialmente, a dimensão ortográfica da língua portuguesa eram espaços de calorosas discussões na seção do jornal. A coluna foi responsável por embates interessantes, pois nem sempre um ou outro leitor reservava as mesmas conclusões para um fato linguístico destacado por Gonzaga Filho.

Mas é em seu romance $A$ Mais Encantadora Mulher que o autor se esmera em defender de que maneira e quais razões justificam o melhor registro gráfico e as motivações seguidas por ele. O livro é constituído de uma estrutura bem peculiar. À ficção em si, que corre por entre 426 páginas, é antecedida por seções menores, nomeadas de "Poucas palavras" e "Simples Nota". Seguem, ao texto do romance, duas outras seções, "Post-scriptum" e "Errata". Nosso olhar se debruça na esteira do que se lê na "Simples Nota" e no "Post-scriptum". O tom de um excerto extraído da "Simples Nota" antecipa as questões sobre as quais nos debruçamos:

Não conheço (em portuguez) dous escriptores, tão uniformes, que, ler um, equivalha accompanhar o outro. Cada penna, cada graphista. mesmo entre aferrados á etymologia, rebenta, quando menos se espera, calorosa divergencia. Egreja, ou igreja? "Com e" gritam uns; ao que, outros retrucarão: "De ecclesia, eigreja, e, pela apherese do e, graphe-se igreja!". E na falta, até hoje, de um lexicon, de suprema, de reconhecida auctoridade, tracta, cada qual, de ir impondo a propria opinião (Filho 1903: 09)².

1 Passaremos a tratar a obra referindo-se a ela apenas como A Mais encantadora mulher.

2 Mantemos as formas gráficas dos textos, sem fazer qualquer ajuste ortográfico, sintático ou de outra ordem. 
A obra, se publicada em 1903, foi sendo costurada, graficamente, muito antes dessa data. $\mathrm{O}$ autor escreve em língua portuguesa, mas ressentido está pelo fato de não encontrar guarita ou acolhida gráfica, no próprio mundo lusófono, pois, para ele, faltava um "lexicon, de suprema, de reconhecida autoridade" (Filho 1903: 09), de modo a imperar uma não-uniformidade gráfica que impunha a cada qual "sua própria opinião". Ainda que um número significativo de escritores grafasse as palavras seguindo padrões etimológicos, o que era homogêneo e visível se desenhava mesmo através de uma "calorosa divergência". Nesse sentido, destacava-se a heterogeneidade no terreno gráfico em que uns gritariam ou outros retrucariam buscando justificar a escolha por "igreja" ou "egreja".

Gonzaga Filho, sentindo que tinha em suas mãos decisões a serem tomadas, convida o leitor, nas seções "Simples Nota" e "Post-impressum", a acompanhar um conjunto de justificativas para o registro gráfico de uma série de palavras que vão compor sua obra A Mais Encantadora Mulher através das quais descreve e justifica a forma gráfica eleita para uma série de palavras, pois, para ele, "Em portuguez, porém, nao há, a quem obedecer" (Filho 1903: 09). Ainda assim, acentua que manteve certa "coherencia [...] da primeira pagina até a ultima" e que cada decisão "não era sem base" (Filho 1903: 431).

Suas escolhas ganharam cores baseadas em motivações de ordem etimológica, fonética, prosódica e a uma proposição bem particular, que ele nomeou de harmonização neo-latina. Nosso estudo será desenvolvido em três momentos distintos. No primeiro, colhemos, na historiografia linguística - especialmente no campo da Grafemática -, vozes com as quais o autor comunga e que acusam a grafia de viver completa anarquia. No segundo momento, descrevemos a série de (des)motivações de sortes variadas que competiam para as decisões/escolhas gráficas de Gonzaga Filho. Reservamos, por fim, uma atenção especial para a inscrição gráfica das palavras cuja justificativa era a harmonização neo-latina.

Em nossas reflexões, também levantamos um repasse historiográfico sobre as obras metaortográficas vigentes na época em que o texto do romancista foi publicado, a algumas das quais o autor faz referência direta. Não podemos ignorar que Gonzaga Filho escreve um romance numa época já demarcada por uma tradição dicionarística muito atuante, inclusive no mundo lusófono, mesmo se as obras lexicográficas registrassem grafias diferentes para a mesma palavra. O que faltava, para ele, era, exatamente, um "acordo" que unificasse a grafia, como já estava a acontecer em outras línguas românicas, a exemplo do espanhol e do francês - e, até mesmo, do inglês.

Essas obras metaortográficas são registros que nos possibilitam descobrir se havia, para além da patente pluralidade de modelos gráficos coexistentes, certas tendências gráficas nos empregos que antecederam o processo de regulamentação ortográfica do português. E quando esses registros são sobremaneira valiosos por virem acompanhados de um relato metalinguístico tão explícito como o que lemos na "Simples Nota" e no "Post-impressum" d' A mais encantadora mulher, é possível ainda acessar algumas das motivações que engendraram a história da nossa própria escrita.

\section{A anarquia ortográfica}

O texto A Mais Encantadora Mulher foi publicado pelas Officinas Typographicas da Companhia A Editora e dedicado, pelo autor, a sua única filha, Cordelia Gonzaga de 
Boscoli. Para Gonzaga Filho, sua obra "aspira a novidade de ser a singella moldura de uma interessante biografia" (Filho 1903: 07), embora demarcada de ficção, tendo sido elaborada com um esforço de tamanha grandeza para "repor com firme pedestal a mais encantadora mulher, de quantas a terra viu" (Filho 1903: 08) somente comparável aos esforços que "De sob as frias areias de Nilo retiraram a celebre estatua grega, que foi caudalosamente asseada e refletida ao museu do Louvre" (Filho 1903: 08). A comparação da deusa Vênus de Milo com sua filha revela o afeto e a dedicação mobilizada na escritura do romance.

Na seção "Post-impressum", encontramos uma série de outros agradecimentos, ainda que esta seção mantenha curso semelhante àquele já visto na "Simples Nota". Nele, por exemplo, encontramos referência à primeira seção:

Disse, na Simples nota, que, forte ou fraco, nao era sem base, que eu anteporia uma fórma a uma outra, adduzindo, entao, varios exemplos expressivos. Deverei, agora, multiplical-os, depois que o leitor, de posse da minha graphica, provavelmente verificou a coherencia, que mantive, da primeira pagina até a ultima? Si não o creio, parece-me de prudencia, que, ao menos sobre meia duzia de irrequietas questiunculas, com toda a franqueza me explique (Filho 1903: 431 - itálico do autor; negrito nosso).

No seio do que podemos nomear de "História da Ortografia", sabemos que o autor não estava sozinho na compreensão dos fatos. Sua defesa fazia coro às vozes e ao tom de uma geração já preocupada com a anarquia e o desalinho instalados no campo gráfico. Gonçalves Viana, filólogo, foneticista e um dos maiores lexicógrafos portugueses do início do século XX, nas primeiras linhas do prefácio de sua Ortografia Nacional. Simplificação e uniformização sistemática das ortografias portuguesas, esclarece: "Este opúsculo não é um tratado de ortografia portuguesa; é antes um inquérito, e a crítica minuciosa, desenvolvida e documentada da actual anarquia ortográfica" (Viana 1904: $\mathrm{V}$ - negrito nosso). E nesse ritmo, acrescenta, nas linhas introdutórias de sua obra:

Nunca existiu ortografia uniforme em Portugal: pretender provar o contrário, ou mesmo insistir na afirmativa, seria obstinação ou ignorância manifesta dos factos. Cada escritor tem usado a sua ortografia, mais ou menos metódica, sem entrarem em linha de conta aquelas que são indiscutivelmente erróneas, ou caprichosas, ou irreflectidas (Viana 1904: V).

Leite de Vasconcellos (1959), em suas Lições de Filologia Portuguesa, cuja primeira edição data de junho de 1911, faz despontar as seguintes observações ortográficas: "É sabido que cada moderno escritor nosso adopta, por assim dizer, sua ortografia. Isto vem já de longe". Mas, para este exímio estudioso, as hesitações naturais da escrita da língua e os entraves vêm de um lugar específico: o "modêlo tirânico do latim", sendo ele também responsável por "embaraços" que resultaram num "mixto na ortografia, não somente na medieval, senão também na dos tempos anteriores" (Leite de Vasconcellos 1959: 205). 
Da etimologia à harmonização neo-latina: Motivações gráficas na escritura de

A mais encantadora mulher (1903) do romancista brasileiro Gonzaga Filho

Também Carolina Michaëlis Vasconcelos, na A ortografia nacional contido nas Lições de Filologia Portuguesa: segundo as preleções feitas aos cursos de $1911 / 12$ e de 1912/13 seguidas das Lições Práticas de Português Arcaico, ressente-se do que para ela é uma "verdadeira calamidade" que domina "os últimos decénios do século", anunciado o fato de que:

Em Portugal não, nem houve nunca, ortografia oficial, uniforme. Só ortografias variadas, mais ou menos sensatamente regradas pelo costume e exemplo de bons autores, ou mais ou menos inçadas de erros, contradições, dislates, caprichos e idiosincrasias [sic] pessoaes. Esse estado pessoal foi tomando proporções de verdadeira calamidade nos últimos decénios do século passado. [...] Houve e ha escritores que na mesma estrofe de um poema, na mesma pájina [sic] de uma novela nos apresentam formas híbridas e contraditórias, não reformadas, meio reformadas ou inteiramente reformadas, como mytho e rythmo; melancólico e eccho; aflito e fructo; próximo e próprio; seria (isto é séria) e Maria; quiz e mês; allucinante e captivante; outomnal e insónia. Uma confusão magna (Vasconcelos s/d:101).

Trata-se, exatamente, de um período bem específico. São os finais do século XIX e Vasconcelos faz referência a um período caracterizado por uma grande difusão de textos escritos marcados por uma grafia sem uniformidade, ora obedecendo a orientações fonéticas, ora etimológicas e/ou pseudoetimológicas (Gonçalves 2003). Aludimos, de seu comentário, a duas questões, e, posteriormente, a uma conclusão que delas pode ser retirada -: 1. o fato da grafia ser regrada "pelo costume e exemplo de bons autores"; 2. o fato das idiossincrasias pessoais, erros e contradições terem tomado "proporções de verdadeira calamidade nos últimos decénios do século passado" (Vasconcelos s/d:101). Nesse sentido, se a escrita de sincronias passadas, no mundo lusófono, obedecia a escolhas sensatas nas mãos dos bons escritores, era, por outro lado, o capricho dos próprios escritores que contribuía para a "confusão magna" visível nos últimos decênios.

Tais caprichos levavam escritores a escreverem "na mesma estrofe de um poema, na mesma pájina [sic] de uma novela [...] formas híbridas e contraditórias, não reformadas, meio reformadas ou inteiramente reformadas" (Vasconcelos s/d: 101).

Do conjunto de citações expostas até o momento por alguns estudiosos que destacamos - efetivamente, poderíamos ter apresentado outros, mas decidimos apenas fazer um recorte -ressaltamos as predicações dirigidas à variação das formas gráficas: "anarquia ortográfica", "confusão magna", formas "errôneas", "caprichosas", "irreflectidas", "contradições", "dislates", "caprichos", "idiosincrasias [sic] pessoaes", "erros", "contradições", "dislates" e "calamidade".

Se a postura dos estudiosos prenunciava a necessidade de uma uniformização gráfica, a forma como tratavam a "variação", naquele momento, patenteava a ideia negativa de que, no terreno da ortografia, a língua vivia um estágio de "caos" (orto)gráfico. Todavia, olhando sob outra perspectiva, é desse próprio caos que extraímos a história da escrita e se entende seu processo de estandardização. Morais de Melo (2018: 64), por exemplo, sobre essa noção secular de que seja caótica a escrita de sincronias passadas, adverte: "O 
maior risco implicado ao se assumir qualquer tema como caótico é sua possível exclusão sumária das agendas de estudo por se considerar improdutiva e inviável sua investigação". Afora essa preocupação, a dita "desordem ortográfica" da escrita, ainda que desordem efetiva fosse, não deveria sustentar uma impossibilidade de fazer científico, a qual estaria baseada na falsa premissa de que do caótico pouco poderia ser dito.

Por essa linha de compreensão, lemos certa "coerência" em Gonzaga Filho, quando anuncia que "forte ou fraco, nao era sem base, que [...] anteporia uma fórma a uma outra" (Filho 1903: 431). E essas bases eram buscadas por ele em fontes ou caminhos justificados: a etimologia, a fonética, a analogia, as obras especializadas, a (não) reprovação das grandes obras lexicográficas e até mesmo os dicionários de referência das demais línguas românicas. De fato, damos nota, por meio de Gonzaga Filho, da existência de obras lexicográficas de reconhecida autoridade em vários idiomas. Por isto, acreditamos que muitos escritores ora confiavam a sua pena aos próprios léxicos já constituídos, ora a soluções gráficas já socialmente aceitas - e expostas em documentos de toda sorte: jornais, cartas, livros de grandes escritores - ora a processos analógicos, ainda que representassem o gosto pessoal de cada escritor para grafar uma forma ou outra.

Decidir uma forma (orto)gráfica segundo o livre gosto, o bel-prazer do escrevente pode soar, para nós, leitores hodiernos (sobretudo se pensarmos na situação da escrita nas últimas décadas), um desatino impensável, uma realidade improvável. Talvez não o seja, contudo, se considerarmos a escrita cibernética. De todo modo, segundo alguns historiadores da língua que integram o que Morais de Melo (2018) denomina de Escola Hispânica, esse era um recurso normal em determinadas centúrias do medievo peninsular. A esse respeito, leia-se a seguinte citação de Sánchez-Prieto Borja (2008: 392, tradução nossa), que se inicia com uma alusão à crítica que o filólogo jesuíta oitocentista Esteban de Terreros y Pando faz a um escritor, público e famoso não apenas na Espanha, cujo nome não revela, devido à forma completamente aleatória de grafar, chegando a escrever, às vezes numa mesma linha, de maneira distinta uma única palavra:

Pero me quiero referir a la postura de ese autor cuyo nombre oculta Terreros que escribe de una manera $u$ otra según el humor con que se levante, que aun en la misma frase presenta una misma palabra de dos maneras diferentes. ¿Es esto un puro disparate, o una manera distinta de la de Terreros de entender la escritura? Una postura como ésta ¿hemos de valorarla sin más como muestra de descuido y arbitrariedad? Desde la perspectiva actual, sin duda diremos que sí, pero considerada en el marco de la historia de la escritura, claramente no. La variatio o variación entre dos formas en proximidad (como vivir y bivir), fue desde antiguo un rasgo de estilo, en absoluto ajeno, por cierto al uso moderno. Si nosotros evitamos repeticiones léxicas y sintácticas, en la Edad Media y aun mucho después alcanzaba esta variación estilística también a la ortografía (Morreale 1978). El sometimiento a regla estable de la ortografía es, precisamente, un signo de los nuevos tiempos, en los que Terreros se inserta plenamente (Sánchez-Prieto Borja 2008: 396)³.

3 "Mas quero me referir à postura desse autor cujo nome oculta Terreros que escreve de uma maneira ou outra segundo o humor com que se levante, que, mesmo na mesma frase, apresenta uma mesma palavra de 
Da etimologia à harmonização neo-latina: Motivações gráficas na escritura de A mais encantadora mulher (1903) do romancista brasileiro Gonzaga Filho

Um dos objetivos do historiador, interessado nesse processo de escolhas gráficas, como bem assenta Ramírez Luengo (2012: 168-9), seria

[...] descobrir no solo la coexistencia de diferentes tendencias ortográficas entendidas como conjuntos de soluciones gráficas aceptadas socialmente en un momento concreto [...], de manera que una de ellas va poco a poco adquiriendo preponderancia e, imponiéndose sobre las demás, adquiere el carácter de norma ortográfica; este proceso histórico - cuyas causas son muchas y variadas, y muy probablemente van desde el aumento de la alfabetización y la escolaridad hasta la mayor difusión de los libros y los textos impresos en la sociedad - conlleva naturalmente una drástica reducción de la libertad existente hasta el momento en el uso de las grafías y, en consecuencia, la adquisición de cierto valor sociolingüístico por parte de esta norma ortográfica (Ramírez Luengo 2012: 168-169)4.

Acreditamos, na linha do que prognostica Ramírez Luengo, que os usos gráficos verificados na obra de Gonzaga Filho possam ser exemplos de tendências que fazem figurar uma espécie de ortografia em transcurso; um exemplo claro de que o português se encaminhava para uma necessária estandardização. Gonzaga Filho era uma voz, dentre outras tantas, que entendia ser necessária a unificação gráfica. Uma passagem digna de nota ressalta esse desejo. Nela, o autor assume que "por mais corriqueiro, não há, em todo este romance, vocábulo algum que deixasse de ter sido o objeto de especial analise" (Filho 1903: 18). E clarifica:

Não posso excessivamente alongar esta simples nota. Si me espraiei mais do que pretendia, foi isso devido a um utopistico anceio, que por ahi vive a sonhar com uma gráfica simplificada, quando tão distante nos achamos da infância da língua, havendo valiosas conquistas a manter e a aperfeiçoar. Não nos falta um systema, em que brilhem os indifferentes, e sim um dicionário, com força de lei, afugentador de plausiveis discussões, e que nos dê o ante-goso de saber, que estamos escrevendo, qual escrevem os doutos (Filho 1903:17-18).

duas maneiras diferentes. É isso um puro disparate ou uma maneira diferente da de Terreros de entender a escrita? Temos de valorar uma postura como essa como mostra de descuido ou arbitrariedade? Da perspectiva atual, sem dúvida diremos que sim, mas considerada no marco da história da escritura, claramente não. A variatio ou variação entre duas formas próximas (como vivir e bivir) foi desde antigamente uma característica de estilo, decerto completamente alheia ao uso moderno. Se nós evitamos repetições lexicais e sintáticas, na Idade Média e mesmo muito depois se alcançava essa variação estilística também na ortografia (Morreale 1978). A submissão a uma regra estável de ortografia é, precisamente, um signo dos novos tempos, nos quais Terreros se insere plenamente" (Sánchez-Prieto Borja 2008: 396 - tradução nossa).

4 " "...] descobrir não apenas a coexistência de diferentes tendências ortográficas - entendidas como conjuntos de soluções gráficas aceitas socialmente em um momento concreto [...], de maneira que uma delas vai pouco a pouco adquirindo preponderância e, impondo-se sobre as demais, adquire o caráter de norma ortográfica; este processo histórico - cujas causas são muitas e variadas, e muito provavelmente vão desde o aumento da alfabetização e da escolaridade até a maior difusão dos livros e dos textos impressos na sociedade - implica naturalmente uma drástica redução da liberdade existente até o momento no uso das grafias e, consequentemente, a aquisição de certo valor sociolinguístico por parte desta norma ortográfica” (Ramírez Luengo 2012: 168- tradução nossa). 
Sonhava Gonzaga Filho com uma "gráfica simplificada", num anseio de seguir um dicionário que afugentasse a variedade gráfica. Mas seu desejo não implicava olvidar os trabalhos árduos e de custoso valor já construídos no campo da dicionarística, reconhecendo, assim, as "valiosas conquistas a manter" (Filho 1903:17-18) e, dessas conquistas, a necessidade de aperfeiçoá-las. Para Gonzaga Filho, não nos "falta um systema, em que brilhem os indifferentes, e sim um dicionário, com força de lei, afugentador de plausiveis discussões" ainda que por ela mesma engendradas (as plausíveis discussões). Não se trata, assim, de um caos indigente ou de um corpo desinformado, mas de grafias constituídas no e pelo sistema da língua portuguesa. Há, assim, um sistema ortográfico, uma ordem que, dele e nele, possa ser estabelecida. Necessário se faz eleger e normatizar uma delas, movimento que já se estabelecera em outros idiomas, como explana o autor:

Complicadissima é a orthographia ingleza, nada facil a dos francezes; entretanto, com os livros de Webster e da Académie Française, qualquer estudioso sente-se no mesmo pé de egualdade do hespanhol, que dispõe, do que andamos impensadamente a namorar (Filho 1903:18).

As línguas inglesa, francesa e espanhola, na época, seguiam, de modo mais rigoroso, dicionários dedicados à ortografia. $\mathrm{O}$ inglês dispunha do dicionário An American Dictionary of the English Language, publicado pelo lexicógrafo Noah Webster, nos anos de 1828; o francês, do Dictionnaire de l'Académie Française, cujas primeiras tendências aparecem em tons de uniformização nos anos de 1690, sob chancela da Académie Française; já o espanhol buscava a implantação de uma norma gráfica de forte aceitação e disseminação, no mundo hispanófono, pelas mãos da Real Academia Española (a RAE, fundada em Madrid, em 1714).

A autoridade do Dictionnaire de l'Académie Française, por exemplo, impediria, nas palavras de Gonzaga Filho, que um francês fizesse "escola contra o estatuído que apenas ensina "physionomie, chevallier, anevrisme, donner, souffrir, falloir, etc.", caso decidisse grafar "physiognomie, chevalier, anévrysme, etc., ou doner, soufrir, faloir" (Filho 1903: 09). O gosto pessoal deve dar lugar a uma padronização elaborada por uma obra lexicográfica "do que andamos impensadamente a namorar". Esse namoro flertava, de igual modo, com o surgimento de instituições que se ocupassem em uniformizar o sistema ortográfico. Em Portugal, essa uniformização passaria pelas mãos da Academia das Ciências de Lisboa; no Brasil, pelas futuras missões da Academia Brasileira de Letras.

\section{Traços de uniformização gráfica para $A$ mais encantadora mulher}

Do leque de orientações possíveis que subjaz os usos gráficos de Gonzaga Filho, percebe-se - com base nas duas notas de caráter metaortográfico, a "Simples Nota" e o "Post-impressum" - uma afeição predominante pelas soluções motivadas pelo étimo. $\mathrm{Na}$ década em que escreveu seu romance, já existia um acervo qualitativo de obras lexicográficas de cariz etimológico, mas Gonzaga Filho demonstrava uma clara com- 
Da etimologia à harmonização neo-latina: Motivações gráficas na escritura de

A mais encantadora mulher (1903) do romancista brasileiro Gonzaga Filho

preensão de que esse caminho não poderia ser o único a ser seguido na formação de um sistema ortográfico. Assim, seu antigo e "querido estandarte" - o autor já fora um defensor que a grafia deveria seguir o caminho da etimologia - que comandava a origem vocabular cedia espaço a talhes gráficos já convertidos "no mais generalizado uso", como ele próprio assume:

Superficial exame classificar-me-ão entre os etymologistas. De feito, o sou; e já fui intransigente, que pugnava por charta, chorda, mactar, mês, português, París, chirurgia, etc., contra o que se converteu no mais generalizado uso, isto é, carta, corda, matar, mez, portuguez, Pariz, cirurgia, etc. Sem embargo, si aqui ainda empunho o antigo e querido estandarte, busquei fugir á pecha de exquisitão, passando a acceitar algumas dessas defeituosas formas. Lancem, pois, os benevolos leitores á conta de tal tolerancia quaesquer apparentes cincadas, e creiam que, forte ou fraca, não é sem base que anteponho uma grafia a outra (Filho 1903: 09).

No decorrer do texto, veremos a palavra "popular" juntar-se à expressão "generalizado uso". Isso ocorre já no início da "Simples Nota", quando o autor defende sua posição mediante a grafia da palavra "afastar": "Afastar-Com um só $f$, por me parecer palavra popular. A etymologia (Moraes) abstare ${ }^{5}$ fere a regra, de que $b$ latino não degenerou em $f$ " (Filho 1903:10 - itálicos do autor; negrito nosso). Sabendo-se da formação em Letras de Gonzaga Filho, entende-se o uso de termos científicos que nomeiam os diferentes processos de mudanças fonéticas. Assim, alinham-se, no decorrer do texto, os seguintes termos: aférese, degeneração, eufonia, geminação, barbarismo, assimilação, síncope, apócope, dentre outros.

Gonzaga Filho nomeia, em primeira ordem, para justificar a grafia da palavra "afastar", o etimologista "Moraes". Ao panteão dicionarístico destacado na "Simples Nota", juntam-se: $1^{\circ}$ Antônio Morais Silva, responsável por reformar o Diccionario da Lingua Portugueza, de composição original do padre D. Rafael Bluteau. Foi o primeiro dicionário organizado por um estudioso brasileiro e teve sua primeira edição publicada nos idos de 1789. Para Verdelho (2003), é a mais importante obra de referência na história da dicionarística de língua portuguesa. Falar em Moraes era como falar Aurélio hoje, ou até mesmo Houaiss, ou, para outros idiomas, Michaelis, Littré; $2^{\circ}$ Francisco José Freire que, sob o nome de Cândido Lusitano, publicou, em dois volumes, nos anos de 1765, o Diccionario poetico, para uso dos que principião a exercitar-se na poesia portugueza: obra igualmente util ao orador principiante; $3^{\circ}$ Francisco Júlio Caldas Aulete, que iniciou um projeto de publicação, em 1881, do Diccionario Contemporaneo da Lingua Portugueza; $4^{\circ}$ Frei Domingos Vieira, autor do Grande Diccionario do Portuguez ou Thesouro da Lingua Portugueza, publicado em 1871.

Apesar de ter suas obras de referências seletas, diletas, há situações que deixam patente a oscilação do autor entre acompanhar a etimologia ou seguir o uso geral de determinadas grafias. Este é o caso, também, da escrita de palavras cuja desinência é

5 Cunha (2010: 16) remonta o verbo ao século XIII (aparecendo, portanto, já nos primeiros registros escritos do português), mas declara como obscura sua origem. 
composta por "z", "embora saiba, que com s é o correcto" (Filho 1903: 16). E assim, justifica sua escolha gráfica:

Accompanho, os que com z fecham terminações longas: ananaz, rapaz, elle traz, intrepidez, francez, portuguez, elle fez, matiz, feliz, liz (flor de), eu fiz, retroz, foz, elle poz, cruz, luz, andaluz, eu puz, elle produz, etc. Exceptuo: fas (por faz ou nefas), aliás, assás, trás, otrás, detrás, has, tu dás, tu estás, as segundas do futuro tu serás, amarás, ferirás, venderás, porás, através, Moysés, revés, tu dês, tu dês, tu les, três, gurupés, após, clós, flos, vós, nós, obus, pus, jus, Jesus, vis, tris, flux e sus. Com ter seguido tal regra, que me levou ás graphias paiz, portuguez, Pariz, francez, etc., não se conclue, que, nos vocabulos derivados, me esqueça de restabelecer, o que mais consentaneo é com a etymologia, pois escrevo: paisagem, aportuguesar, parisiense, francesismo, etc., cumprindo-me explicar, que, devido a essa dicta regra, escrevendo eu marquez, e dahi marqueza, conformei-me ao uso geral nas graphias princeza, baroneza, duqueza, prioreza, alteza, embora saiba, que com $s$ é o correcto (Filho 1903: 16).

Vocábulos com as letras " $z$ " ou "s" recebem atenção especial O poeta diz não conhecer substantivos em "aza", de sorte que sua escolha por "brasa" também é sugerida pelo francês e pelo castelhano (também o antigo alemão). No seguinte excerto, dessa vez, o autor recorre à etimologia da palavra latina "ansam", para justificar a grafia de "asa":

Asa - Não poderia provir de alam; o $l$ medial ou é resistente (taleam, tala; militiam, milicia) ou syncopa-se (aquilam, águia, palum, pau; ou degenera-se em $r$ (lilium, lirio.; cumulum, comoro). Degeneração em z (como querem os grafistas de aza), é tudo, que ha de prohlematico. De alam, ala, alar; de modo nenhum asa, que prende-se a ansam. Também ficou em evidencia, o porque escrevo aso, o verbo asar, asado, asadamente. Com z, az (carta de jogar) e azar (acaso, sorte), de arabica origem. (Filho 1903:11 - itálico e negrito do autor)

Defende o autor a grafia de "asa", diferentemente de muitos etimologistas que assinalavam "aza". De fato, Morais (1789) e Vieira (1871), e.g., preferem a notação de "aza". Para Gonzaga Filho, o "l" de "ala", jamais teria se degenerado em "s": "Degeneração em z (como querem os grafistas de aza), é tudo, que ha de problematico". Casos de degeneração em " $r$ " podem ser observados em outros ambientes linguísticos: "lírio" é vocábulo cujo "l" sofre degeneração do "l” medial que integra a palavra latina "lilium" (lilium>lírio); "águia", por sua vez, advém da síncope do "l" medial da palavra "aquila" (aquila>águia). A palavra portuguesa "asa" seria originária de "ansam", daí a manutenção do "s" .

$\mathrm{Na}$ "Simples Nota", Gonzaga Filho reserva quase seis (06), das quatorze (14) laudas, para destacar, em ordem alfabética, um conjunto de palavras cuja grafia não figu-

6 Anotamos a curiosidade que marca a palavra "ala", a partir do operoso dicionário Oxford Latin Dictionary (Glare 1982). Ela é originária dum processo de sincronização do vocábulo latino "axilla" (parte superior e inferior do braço, onde se unem os braços ao ombro"), após sofrer síncope. 
Da etimologia à harmonização neo-latina: Motivações gráficas na escritura de

A mais encantadora mulher (1903) do romancista brasileiro Gonzaga Filho

rava na famosa obra de Caldas Aulete. Nestes termos, encontramos: "Dahi, posso avisar, que os seguintes, embora portuguezes e empregados com estricta propriedade, não figuram na edição de 1881 do Diccionário Contemporaneo, do operoso Caldas Aulete" (Filho 1903:18). Desse conjunto lexicográfico, destaquemos um recorte particular, pois nele o autor retoma uma questão já há muito referida por ele e já destacada na seção Questões de Linguística, do jornal O Globo, citado no início de nossa investigação.

Acastanhar e acastanhado - Aciaria (lat. aciarium; fr. aciérie)-Açodamento Acoroçoador e acoroçoante - Addenda- Alanhador e alanhante - Alheamento - Almasso (papel almasso) - Alteação- Altruismo, altruista e altruistico - Alucinadamente - Alvinitente - Amantetico - Ambular - Amnesiado (desmemoriado) e amnesiar -Amistoso -Angelitude (por mim, ha annos, proposto) -Anormalizar Ancinomico -Antisepsia -Anthropologismo - Anthropometria e anthropometrico - Apetrecho (petrecho) - Aphasico-Arapuca (armadilha, no Brasil, para pequenos animaes) - Arranjativo -Articulista - Asepsia e asséptico - Asphyxico -- AtavicoAtordoante- Attenuativo -Aviador - Avinhado (ou curió, passaro do Brasil) [...] (Filho 1903: 18 - itálico do autor; negrito nosso)

Damos atenção ao vocábulo "angelitude". O autor registra, em A Mais encantadora mulher, o fato de já haver proposto o neologismo "angelitude" em outras situações. Encontramos na coluna do jornal "O Globo", na seção Questões de Linguística, vinte anos antes da publicação de $A$ Mais encantadora mulher, a sugestão de Gonzaga Filho, aqui descrita:

De todas as palavras, porém, que não tenha encontrado nem em diccionarios portugueses, nem em auctor de nota, uma há que já tive ocasião de empregar, sendo incrível que não figure em linguagem de christãos, onde há anjo, angelico etc. É o substantivo - angelitude ou angelidade. Reparem na pergunta e resposta seguintes: o que é que mais te arrebata na madona que vês neste quadro? A angelitude (O Globo 1882: 03)

Curiosamente, encontramos uma nota expressa em edição avulsa do jornal Gazetinha noticiando o exercício e o engajamento do escritor na luta e registro da criação do referido neologismo:

O proponente do necessario neologismo angelitude que não existe nos diccionarios e bons autores portugueses, desejando que ele crie raizes, enriquecendo ainda mais a nossa bella língua, pede-nos que publiquemos o seguinte:

$[\ldots]$

Satisfazemos com todo gosto ao pedido do distinto autor das Questões de linguistica, do Globo, sinceramente magoados por não podermos dar a S.S maior prova de...angelitude (Gazetinha 1882: 01 - itálico do jornal).

7 Cf. Questões de Linguística, In O Globo - sexta-feira, 3 de fevereiro de 1882. 
Outra notação significativa daquele recorte particular, além da palavra "angelitude" destacada, são os registros gráficos referentes aos nomes de pássaros brasileiros. Era uma forma de não só fazer referência, mas de normalizar o registro da fauna brasileira. Em toda a "Simples Nota", deparamo-nos com dezoito (18) registros, os quais assinalamos: Avinhado (ou curió), Bemtevi, Bicudo, Bigodinho, Caboclinho, Canario da terra, Colleiro do brejo, Corrupião, Encontro (ou nhapim, ou soldado), Fradinho, Gallo da serra, Gaturamo, Grauna, Palanque, Papa-capin (ou simplesmente colleiro), Pintacilgo da terra, Sacy e Tico-tico.

No processo de fixação de balizas em sua seara grafemática, não só a filólogos e dicionaristas recorria Gonzaga Filho; poetas e escritores renomados são frequentemente evocados pelo autor no seu percurso de decisões gráficas, dentre os quais podemos citar: 1. escritores brasileiros: Costa e Silva, José de Alencar e Francisco Otaviano; 2. escritores portugueses: Castelo Branco, Almeida Garrett e Bernadim Ribeiro.

Obras metaortográficas, propostas neológicas, poetas e ficcionistas são, portanto, algumas das fontes que vão configurando o mosaico-moldura de decisões gráficas construído na "Simples Nota" e no "Post-impressum" de A mais encantadora mulher. E outras substâncias há mais nesse compósito. Pela corrente da má pronunciação, ou do "falar mal", o autor faz uma predileção gráfica para a escrita da palavra "involver": "Involver, desinvolver - De involvere fez a prolação portuguesa involver. Quem diz envolver, será capaz de pronunciar envento, enteresse" (Filho 2013: 11 - negrito do autor). Em certos ambientes, na língua portuguesa, as letras "i" e "e" são pronunciadas pelo par fonético "/e/, /i/". Gonzaga Filho alia a forma gráfica a uma forma correta de pronunciar e, de certo modo, segue uma longa tradição já manifesta no próprio mundo lusófono, quando consideramos as grandes obras cujo objetivo era ensinar a forma correta de pronunciar as palavras. Dentre essas obras, merece destaque a de Madureira Feijó que publicou, nos anos de 1734, seu manual, referenciado na história da ortografia portuguesa, Orthographia; ou, Arte de escrever: e pronunciar com acerto a lingua portugueza para uso do excellentissimo duque de Lafoens, no qual se encontram compilados os erros mais comuns na fala seguidos de respectivas correções ${ }^{8}$.

Nesse ritmo da pronunciação correta, o autor exibe sua preleção para a escrita da grafia de "surrir, surriso": "Surrir, surriso - A etymologia surridere deu a primeira licção, e a portugueza prosodia repetiu-a, desde que approximou taes vocabulos do fr. sourire. Fala mal quem diz sôrrir, em vez de surrir" (Filho 1903: 10). Aqui, Gonzaga Filho utiliza a escrita da palavra francesa e o modo como as letras "o" e "um" (ou) juntas, são pronunciadas: /u/. A aproximação ou o afastamento prosódico com alguma das línguas latinas vai responder, em certa medida, pela noção de harmonização neolatina, manifesta através da sonoridade ou da grafia, conforme vemos na atenção reservada à grafia de palavras com letras "s" e "z". Tomamos-lhe alguns exemplos:

Brasil, brasileiro - Formigam estirados artigos em favor de $s$, e também de $z$ que é pura graphia ingleza. Mas o bom-senso litterario nos está bradando, a não

8 Cf. a leitura de Gonçalves (2003) sobre a produção de Madureira Feijó. 
Da etimologia à harmonização neo-latina: Motivações gráficas na escritura de

A mais encantadora mulher (1903) do romancista brasileiro Gonzaga Filho

quebramos a harmonia neo-latina: escreveram, escrevem e escreverão Brésil o francez, Brasile o italiano, e Brasil o hespanhol (Filho 1903: 11 - negrito e itálico do autor; sublinhado nosso).

Brasa - O velho allemão bras, o fr. braise, e o cast. brasa ensinam $s$. Nem conheço substantivos em "aza"; sim, casa, asa, rasa, vasa, grafam-se todos com $s$. (Filho 1903: 11 - negrito e itálico do autor).

Assim como o francês, o italiano e o espanhol, a língua portuguesa integra o grupo de línguas umbilicalmente ligadas ao latim. Se essas línguas "escreveram, escrevem e escreverão" Brésil (francês,), Brasile (italiano) e Brasil (espanhol), o bom senso literário pediria a manutenção de uma "harmonia neolatina", de modo a manter a letra "s", e não "z", na palavra "Brasil" e naquelas que dela derivam, como o termo pátrio "brasileiro". Assume, assim, uma posição a favor dos "estirados artigos em favor de s", haja vista que "Brazil" com " $z$ " seria puramente uma grafia inglesa, língua ligada a outro grupo linguístico (anglo-saxônico) que não o latino.

A harmonização latina é convidada como defesa para a manutenção de certos agrupamentos geminados. O autor é contra a grafia das geminadas e, quando a realiza, assinala ser por pura questão etimológica, sem, contudo, preservar a prosódia castellana, presente em palavras como "estallar, solluçar, callar". Assim se defende: "Ora, nao devendo guiar-me pela simplicidade castellana, que só geminou letras que tem prosódico valor, não desprezei a lição daqueles três idiomas" (Filho 1903: 432). Refere-se ao francês, italiano e espanhol.

A preservação das geminadas, portanto, acompanha a direção para uma harmonização neo-latina - advinda ou não da etimologia; daí sua inclinação pelas grafias de accompanhar (fr. accompagner, it. accompagnare) e anniquilamento (fr. annihiler, it. annichilare).

Esse contraponto com outras línguas, latinas e não latinas, acentua - no caso em que Gonzaga Filho descreve a grafia da palavra "letra" - as já (naquela alvorada do século XX) existentes tensões entre o espanhol e o português:

Lettra - Vindo, alphabeticamente, lit antes de litt, clarissimo, que os melhores lexicons, ao chegarem a littera, mandem ver, o que já foi definido, isto é litera. Indubitavel, porém, que, em optimo latim, campeam ambas as graphias; e, dahi, mesmo para os etymologistas, facultativo será, escreverem lettra, ou letra.[...] optando pela graphia latina littera, nao desafiaremos a natural surpresa do francez lettre, do italiano lettera, do inglez letter, e do allemão letter. De minha parte, escrevo e escreverei lettra, litterario, litteral, litteratura, solettrar, etc., com $t t$ (Filho 1903: 431-432).

Gonzaga Filho mantém, independente do registro já proposto nos léxicos, seu gosto pessoal pela geminação, assegurando a harmonização que tanto preza. Daí opta por não desafiar a etimologia, por ele mesmo em tantos momentos desafiada, e anuncia, sob a ordem da "natural surpresa do francez lettre, do italiano lettera" e de outras lín- 
guas não românicas, a exemplo do inglês (letter) e do alemão (letter), a grafia de outras palavras construídas sob o mesmo étimo de "lettra": litterario, litteral, litteratura e solettrar.

Já para o caso de grafia de palavras estrangeiras, o autor é contra o seu aportuguesamento, como seria o caso de toilette, coupé, dentre outras.

Toilette, coupé, bouquet, buffet, crochet, chalet - Em justos logares, permetti respiro a taes vocabulos, que, de ha muito, deixaram de ser perseguidos, por se terem serviçalmente abrigado para dentro da mais usual linguagem, e, si aqui os alinhei, foi, para accentuar, que lhes respeito a integridade de origem. Tenhamos a maxima intransigencia contra o emprego de palavras extrangeiras desnecessarias; as pouquissimas, porém, que lograrem vingar, sem soffrerem alteração prosodica, essas não as reduzamos a verdadeiros barbarismos graphicos, visto que nunca poderemos esperar, que qualquer penna, mesmo de modesta instrução, se resigne ao ridiculo de escrever - toaléte, cupê, buquê, splin, uotar-prufe, iánque, etc (Filho 1903: 432).

Até mesmo para grafar nomes próprios de origem inglesa, a exemplo de "Windsor", "Newton" e "Glasgow, iniciados pela letra "W", prefere Gonzaga Filho manter as referidas formas gráficas. Para ele, não haveria necessidade de transliteração da letra "w" para seu correspondente sonoro "u", na língua portuguesa. Assim, evita as seguintes formas gráficas, correspondentes aos nomes próprios citados: "Uindsor", "Neuton" e "Glasgou". Acentua Gonzaga Filho que "o alphabeto portuguez, dos etymologistas, pôde, desde a infancia da lingua, enriquecer-se com o w, embora elles só o tenham empregado, precisamente nos vocabulos anglo-saxonios. Prova-o a correcta graphia "wisigodos", de Alexandre Herculano" (Filho 1903: 432).

Os esforços do romancista "não se reduziram apenas à gráfica, e que também se estenderam ao farto vocabulário de que se compõe este livro" (Filho 1903: 22). E se busca uma certa harmonia, ele o faz de igual modo seguindo escritores como José de Alencar que assinalou ser a harmonia "uma das primeiras bellezas da língua" (Filho 1903: 22).

Não sem se furtar, prepara-se para o fechamento de seu texto em notas desconcertantes:

Desgosta, aos que buscam algo mais, do que eslagartar a syntaxe, reconhecerem a sem razão, com que os dicionários restringem os recursos do nosso opulento idioma; ora obsoletando uteis palavras (ternal, por exemplo, o mesmo que ternario, e que perfeitamente se ajeitará com a parentela dual, decimal, vigesimal, etc.), e ora nem fazendo mensão de consagradas variantes para prova, e que está para grade qual covil, hastil para haste, etc. Ve-se, pois, que os meus esforços não reconduziram apenas a gráfica, e que tambem se extenderam ao farto vocabulario, de que se compõe este livro (Filho 1903: 22).

O autor, nas suas 14 páginas da "Simples Nota", aborda questões de natureza variada. Referir-se a todas excederia os limites de nosso texto. Preferimos, então, encerrá-lo 
com as últimas palavras da "Simples Nota", que parecem evidenciar que, assim como para este trabalho, esgotar o tópico - na extensão/construção de um léxico próprio para sua obra, no caso de Gonzaga; na devassa exaustiva de todos e cada um dos léxicos por ele postos na ribalta, em nosso caso - não era sua intenção:

E fecharei esta Simples nota, porque si, em vez de distrações com a leitura de um decente romance, o leitor carecer de se entregar a um escudo raciocinado, segundo os princípios hodiernos da sciencia da linguagem, encontrará na Grammatica Portugueza, do hábil professor José Ventura Boscoli, um trabalho completo, e que já teve a consagração dos competentes (Filho 1903:22).

\section{Considerações finais}

Apesar de ter suas referências seletas, diletas, há situações que deixam patente a oscilação do romancista Gonzaga Filho entre acompanhar a etimologia ou seguir o uso geral de determinadas grafias. Este foi o caso, por exemplo, da grafia das palavras "princeza, baroneza, duqueza, prioreza, alteza, embora saiba, que com s é o correcto" (Filho 1903: 16). Ainda assim, o romancista não esconde sua afeição por padrões etimológicos e este fato, em ampla medida, brada mais forte em seu discurso. Ao defender a grafia de determinadas palavras obedecendo ao critério nomeado harmonização neo-latina - tomando como parâmetro o francês, o italiano e o espanhol, por exemplo - impera uma significativa figuração etimológica nessa harmonização.

$\mathrm{O}$ autor deixa escapar seu gosto pessoal pela etimologia quando anuncia que as formas de uso recorrente são formas defeituosas. Por outro lado, Gonzaga Filho mantém uma postura linguística aberta às novas formas gráficas. Ampara-se, por isso, em fatores de ordem variada.

Decerto não ousamos defender que Gonzaga Filho evite escolhas pessoais, mas percebemos que suas escolhas guardam justificativas que consideram um sistema linguístico em uma temporalidade sócio-histórica e as camadas que constituem esse sistema - fonética, sintática, morfológica e semântica. A obra de Gonzaga Filho, é, ao fim e à medida, um importante documento sobre a história da grafia que merece atenção, dado o modo como o autor enfrenta as formas gráficas de um léxico ainda não normatizado.

Sem muito referendar, o autor nos conduz à busca de um conjunto de obras metalinguísticas e metaortográficas que se juntavam aos dicionários (lexicons), como foram as gramáticas que espelhavam a língua em sincronias passadas, mesmo que o autor referende apenas a obra de José Ventura Boscoli (1894).

O romance $A$ Mais Encantadora Mulher também explora questões que vão além de preocupações ortográficas, mas essas questões não foram, de fato, objeto de nossa investigação.

Em larga medida, entendemos que Gonzaga Filho faz parte de um panteão de linguistas, cujas contribuições para a história da língua portuguesa ainda estão por serem descobertas, especialmente quando nos deparamos com a postura do romancista (e linguista) mediante fenômenos linguísticos de ordem sintática e semântica, especialmente 
na seção Questões de Linguística, do jornal $O$ Globo (1882). Temos, nessa seção do jornal - sabendo que seu romance continua sendo um chão inesgotável de estudos - um espaço de frutuosas e significativas investigações.

\section{BIBLIOGRAFIA}

ACADÉMIE FRANÇAISE (1871): Dictionnaire de l'Académie. Paris: Imprimeur ordinaire du Roy de l'Academie Française. [https://www.dictionnaire-academie. $\mathrm{fr} /]$.

ACADEMIA REAL DAS SCIENCIAS DE LISBOA (1793): Diccionario da lingoa portugueza, publicado pela Academia Real das Sciencias de Lisboa, 1 vol. Lisboa: na officina da mesma Academia Real das Sciencias de Lisboa. [https:// purl.pt/29130].

AUlETE, Júlio Caldas (1881): Diccionario Contemporaneo da Lingua Portugueza feito sobre um plano inteiramente novo, 2 vol.. Lisboa: Imprensa Nacional.

BOSCOLI, José Ventura (1894): Grammatica Portugueza: Estudo Racionado segundo os princípios Hodiernos da sciencia da linguagem. Rio de Janeiro: Imprensa Nacional.

CUNHA, Antônio Geraldo da. (2010): Dicionário etimológico da língua portuguesa. Rio de Janeiro: Lexicon.

FEIJÓ, Madureira (1739): Orthographia ou arte de escrever e pronunciar com acerto a lingua portugueza para uso do excelentissimo Duque de Lafoens. Lisboa: Luis Secco Ferreira.

FILHO, Gonzaga (1903): A mais encantadora mulher - um romance para senhoras. Lisboa: Officinas Typographicas da Companhia "A Editora".

FREIRE, Francisco José (1765[1794]): Diccionario poetico, para uso dos que principião a exercitar-se na poesia portugueza: obra igualmente util ao orador principiante. Segunda edição correcta. Lisboa: Of. Simão Thadeo Ferreira - 2Tomos em 1 vol. [https://purl.pt/13947].

GAZETINHA (1882): "Publicação diária". Número avulso, Ano I, no 31. [http:// memoria.bn.br/DocReader/Hotpage/HotpageBN.aspx?bib=706850\&pagfis=433\&url=http://memoria.bn.br/docreader\#/].

GLARE, P. G. W. (1982). Oxford Latin Dictionary. Editor Oxford.

GONÇALVES, Maria Filomena (2003): As ideias ortográficas em Portugal. De Madureira Feijó a Gonçalves Viana (1734-1911). Lisboa: Fundação Calouste Gulbenkian/Fundação para a Ciência e a Tecnologia.

LEITE DE VASCONCELLOS, José (1959): Lições de Filologia Portuguesa. Rio de Janeiro: Livros de Portugal.

MORAIS DE MELO, Felipe (2018): Nas trilhas da escrita: reedição e análise grafemática das cartas oficiais norte-rio-grandenses (1713-1950). 2018. 961f. Tese (Doutorado) - Programa de Pós-graduação em Estudos da Linguagem, Universidade Federal do Rio Grande do Norte, Natal.

MORREALE, Margherita (1978): "Transcendencia de la variatio para el estudio de la grafía, fonética, morfología y sintaxis de un texto medieval, ejemplificada en 
Da etimologia à harmonização neo-latina: Motivações gráficas na escritura de A mais encantadora mulher (1903) do romancista brasileiro Gonzaga Filho

el ms. Esc. I.I.6". Annali de la Facoltà di Lettere e Filosofia dell'Università di Padova, II, p. 249-261.

O GLOBO (1882): Orgão da Agencia Americana Telegraphica dedicado aos interesses do Commercio, Lavoura e Industria (RJ). [http://memoria.bn.br/docreader/ DocReader.aspx?bib=369381\&pagfis $=0]$.

RAMÍREZ LUENGO, José Luis (2012): "Notas sobre las tendencias gráficas del español colombiano en la época de las Independencias (1830)”, J. L. Ramírez Luengo (coord.). Por sendas ignoradas. Estudios sobre el español del siglo XIX. Lugo, Axac, 2012, p. 167-182.

SÁNCHEZ-PRIETO BORJA, Pedro. (2008): Paleografía y ortografía en la obra de Terreros. Esteban de Terreros y Pando: vizcaíno, polígrafo, jesuita. III Centenario: 1707-2007. Bilbao: Universidad de Deusto.

SILVA, Antonio de Moraes Silva (1789): Diccionario da lingua portugueza composto pelo padre D. Rafael Bluteau, reformado, e accrescentado por Antonio de Moraes Silva, natural do Rio de Janeiro (Volume 1: A - K). [https://digital.bbm. usp.br/view/?45000008422\&bbm/5412\#page/44/mode/2up].

VASCONCELOS, Carolina Michaëlis de Vasconcelos (s.d.): Lições de Filologia Portuguesa: segundo as preleções feitas aos cursos de 1911/12 e de 1912/13 seguidas das Lições Práticas de Português Arcaico. Lisboa: Martins Fontes.

VERDELHO, Telmo (2003): “O dicionário de Morais Silva e o início da lexicografia moderna". In: História da língua e história da gramática - actas do encontro. Braga: Universidade do Minho/ILCH, p.473-490.

VIANA, Aniceto dos Reis Gonçalves (1904): Ortografia nacional: simplificação e uniformização sistemática das ortografias portuguesas. Lisboa: Viúva Tavares Cardoso.

VIEIRA, Frei Domingos (1871): Grande Diccionario Portuguez ou Thesouro da Língua Portugueza. Editora Porto, [Em Casa dos Editores Ernesto Chardron e Bartholomeu H. De Moraes; Rio de Janeiro. [https://bibdig.biblioteca.unesp.br/handle/10/28254].

WEBSTER, Noah (1828): An American Dictionary of the English Language. New York: Published by $\mathrm{S}$. Converse.

\section{PERFIL ACADÊMICO E PROFISSIONAL}

Professora de Línguas e Literaturas Clássicas e Linguística Românica na Universidade Federal do Rio Grande do Norte (UFRN), em Natal, Brasil. Tem publicado diversos artigos, no Brasil e no exterior, e orienta dissertações e teses no domínio dos estudos do texto e dos discursos. Também desenvolve pesquisas no campo da tradução e da história das ideias linguísticas.

Data de recepção: 20-01-2021

Data de aceitação: 21-05-2021 